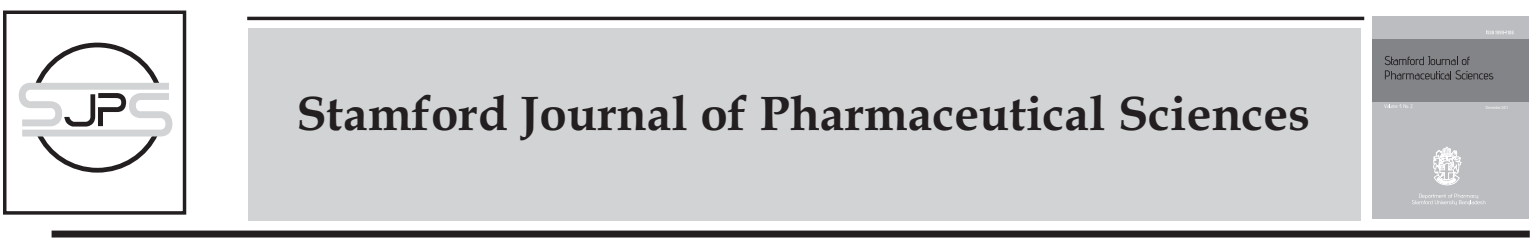

\title{
Preparation and comparative evaluation of liquisolid compacts and solid dispersions of Valsartan
}

\author{
${ }^{*}$ P. K. Lakshmi, Ch. Srinivas, B. Kalpana \\ Department of Pharmaceutics, G. Pulla Reddy College of Pharmacy, Mehindipatnam \\ Hyderabad - 500 028, Andhra Pradesh, India.
}

Original Research Article

\begin{abstract}
The aim of the present study was to increase the solubility of a poorly water soluble BCS class II drug, valsartan. Liquisolid technology and solid dispersion by kneading method were techniques used to improve the solubility of the drug by using non-volatile solvents and some hydrophilic carriers. Liquisolid compacts were prepared by dissolving the drug in suitable non volatile solvents. The various non volatile solvents used were PG, PEG, and glycerine. The carrier coating materials play an important role in improving the solubility of the drug. The dissolution rate of the drug was increased by using propylene glycol as non-volatile solvent at 20:1 ratio of carrier to coating material. Solid dispersion by kneading method were another attempt to improve solubility the various carrier materials used were PVP K 30 , PEG 6000 and mannitol, these carriers are used in various ratios to improve its solubility. The dissolution rate of drug using solid dispersion kneading method with mannitol was increased at 1:3 ratio. The DSC and FTIR studies revealed no drug excipients interactions, whereas XRD revealed the reduced crystalinity of drug, which showed enhanced solubility. From the results it was concluded that the liquisolid compacts enhanced the solubility of valsartan in comparison to traditional solid dispersion method.
\end{abstract}

Keywords: Valsartan, liquisolid compacts, solid dispersions.

\section{INTRODUCTION}

One of the major challenges of present pharmaceutical research is to enhance the dissolution profile, absorption efficiency and bioavailability of water insoluble drugs (Yalkowsky and Rubino, 1985). The solubilitydissolution behavior of a drug is frequently the rate-limiting step to absorption of drugs from the gastrointestinal tract for orally administered drugs (Sugawara et al., 2005; Youn et al., 2006). Poor aqueous solubility has always been a very challenging obstacle as it is together with membrane permeability, an essential factor in the limitation of a drug's bioavailability following oral administration. Since an increasing number

\section{${ }^{*}$ Corresponding Author:}

P.K.Lakshmi, M.Pharm, PhD

Prof and Head, Department of Pharmaceutics

G. Pulla Reddy College of Pharmacy

Mehdipatnam Hyderabad

Andhra Pradesh, India 500028

Ph:09000044452,drlakshmisuresh@gmail.com of newly developed drug candidates in preclinical development phases present poor water-solubility characteristics, there is a great need for formulation approaches to overcome this factor (Hecq, 2006). The aim of the present study was to increase the solubility of a poorly water soluble BCS class II drug, valsartan. During the past few years many techniques have been developed such as drug micronization, solid dispersions, coprecipitation, lyophilization, and microencapsulation, use of prodrug, drug derivetization processes and inclusion of drug solutions into soft gelatin capsules (Spireas and Sadu, 1998) to improve the solubility and bioavailability. Solid dispersion (SD) technology is a well known process used to increase the dissolution kinetics and oral absorption of poorly water soluble drugs using water soluble inert carriers (Aleti et al., 2011). Formulation of liquisolid compact (LS) is a novel "Powder 
Table 1: Formulation of LS compacts of valsartan.

\begin{tabular}{|c|c|c|c|c|c|c|}
\hline $\begin{array}{l}\text { Formulation } \\
\text { no }\end{array}$ & $\begin{array}{l}\text { Conc. of valsartan } \\
\text { in various solvent } \\
(\%)\end{array}$ & $\begin{array}{l}\text { Excipient ratio } \\
(R)=\text { carrier: } \\
\text { coating }(Q / q)\end{array}$ & $\begin{array}{l}\text { Liquid load } \\
\text { factor }\left(L_{f}\right) \\
\left(L_{f}=W / Q\right)\end{array}$ & $\begin{array}{l}\text { Avicel PH } \\
200(\mathrm{gm}) \\
\left(Q=W / L_{f}\right)\end{array}$ & $\begin{array}{l}\text { Aerosil PH } \\
200(\mathrm{gm}) \\
(\mathrm{q}=\mathrm{Q} / \mathrm{R})\end{array}$ & $\begin{array}{l}\text { Per Tablet } \\
\text { weight } \\
\text { (gm) }\end{array}$ \\
\hline LSVPG 1 & 20 & $5: 1$ & 1.9760 & 0.125 & 0.025 & 0.420 \\
\hline LSVPG 2 & 20 & $10: 1$ & 1.0977 & 0.225 & 0.023 & 0.520 \\
\hline LSVPG 3 & 20 & $15: 1$ & 0.9427 & 0.262 & 0.018 & 0.550 \\
\hline LSVPG 4 & 20 & $20: 1$ & 0.8233 & 0.300 & 0.015 & 0.620 \\
\hline LSVPG 5 & 20 & $25: 1$ & 0.7600 & 0.325 & 0.013 & 0.615 \\
\hline LSVPEG 6 & 20 & $5: 1$ & 1.7066 & 0.150 & 0.030 & 0.450 \\
\hline LSVPEG 7 & 20 & $10: 1$ & 1.024 & 0.250 & 0.025 & 0.550 \\
\hline LSVPEG 8 & 20 & $15: 1$ & 0.9309 & 0.275 & 0.018 & 0.570 \\
\hline LSVPEG 9 & 20 & $20: 1$ & 0.7529 & 0.340 & 0.017 & 0.635 \\
\hline LSVPEG 10 & 20 & $25: 1$ & 0.7314 & 0.350 & 0.014 & 0.645 \\
\hline LSVG 11 & 20 & $5: 1$ & 1.6685 & 0.175 & 0.030 & 0.475 \\
\hline LSVG 12 & 20 & $10: 1$ & 1.1680 & 0.250 & 0.025 & 0.550 \\
\hline LSVG 13 & 20 & $15: 1$ & 0.9733 & 0.300 & 0.020 & 0.600 \\
\hline LSVG 14 & 20 & $20: 1$ & 0.9125 & 0.320 & 0.016 & 0.615 \\
\hline LSVG 15 & 20 & $25: 1$ & 0.8342 & 0.350 & 0.014 & 0.645 \\
\hline
\end{tabular}

Solution Technology" which makes use of liquid medications admixed with suitable carriers and coating materials and formulated into a moderately flowing, dry looking, non adherent and compressible powder forms have increased the drug dissolution rate profiles (Spireas and Bolton, 1999).

\section{MATERIALS AND METHODS}

Valsartan was supplied by Dr. Reddy's Laboratory, Propylene glycol, PEG 4000, Glycerin, Avicel PH 102, Aerosil 200, Cross povidone, PVP K-30, PEG 6000, Mannitol, Spray dried lactose, Methanol, Ethanol were obtained from S.D fine chemicals. Distilled water was of laboratory grade. All materials used were of analytical grade.

\section{Preparation of liquisolid compacts of valsartan}

LS formulations of valsartan were prepared by using non-volatile solvents, and carrier coating materials like Avicel PH 102, Aerosil 200 , cross povidone (Table 1). Desired quantities of previously weighed solid drug and the liquid vehicle were taken in a beaker and heated to 80-90o C with constant stirring, until a homogenous drug solution was obtained. The mixing procedure was conducted in three stages.

In the first stage, weighed quantity of carrier material (Avicel PH 102) was blended with liquid medication in order to evenly distribute the liquid medication into the powder.

In the second mixing stage, calculated quantities of coating material (Aerosil 200) was added to the system and blended for 2 min. The liquid powder admixture was left undisturbed for approximately $5 \mathrm{~min}$ to allow the drug solution to be absorbed into the interior of the powder particles.

In the third stage, the powder was blended with a calculated quantity of superdisintegrant (5\%) for another $30 \mathrm{sec}$ producing the final LS formulation. The blend was compressed into tablet, at a hardness of $2.5-4 \mathrm{~kg} / \mathrm{cm}^{2}$ on a rotary tablet punching machine with punch size of $11 \mathrm{~mm}$, batch size of 20 tablets were prepared each time (Spireas et al., 1998).

Preparation of solid dispersion by kneading method Drug and carrier in various (1:1), 
Table 2: Formulae of SDs of valsartan with different carriers PVP K- 30, PEG-6000, mannitol.

\begin{tabular}{lllllll}
\hline $\begin{array}{l}\text { Formula code } \\
\text { with PVP }\end{array}$ & $\begin{array}{l}\text { Formula code } \\
\text { with }\end{array}$ & $\begin{array}{l}\text { Formula code } \\
\text { with PVP }\end{array}$ & $\begin{array}{l}\text { formula code } \\
\text { with mannitol }\end{array}$ & $\begin{array}{l}\text { Ratio of } \\
(\mathbf{D}: \mathbf{C})^{\dagger}\end{array}$ & $\begin{array}{l}\text { Wt of the } \\
\text { drug } \\
(\mathbf{m g})\end{array}$ & $\begin{array}{l}\text { Wt of the } \\
\text { carrier } \\
(\mathbf{m g})\end{array}$ \\
\hline SDVPVP-1 & SDVPEG-1 & SDVPVP-1 & SDVMN-1 & $1: 1$ & 40 & 40 \\
SDVPVP-2 & SDVPEG-2 & SDVPVP-2 & SDVMN-2 & $1: 3$ & 40 & 80 \\
SDVPVP-3 & SDVPEG-3 & SDVPVP-3 & SDVMN-3 & $1: 5$ & 40 & 200 \\
SDVPVP-4 & SDVPEG-4 & SDVPVP-4 & SDVMN-4 & $1: 9$ & 40 & 450 \\
\hline
\end{tabular}

(1:3), (1:5), (1:9) ratios, the various carriers employed were PVP K-30, PEG 6000, mannitol were taken in a mortar and few $\mathrm{ml}$ of ethanol was added and triturated vigorously until the damp granular mass was obtained (Table 2). The mixture was then dried in a hot dessicator for further characterization.

\section{Preparation of valsartan directly compressible tablets}

The tablets were prepared using dry granulation (Javadzadeh et al., 2007).

Table 3: Formulae of PMs of valsartan with PVP K-30, PEG 6000, and mannitol.

\begin{tabular}{llllll}
\hline $\begin{array}{l}\text { Formula code } \\
\text { with PVP K-30 }\end{array}$ & $\begin{array}{l}\text { Formula code } \\
\text { with PEG 6000 }\end{array}$ & $\begin{array}{l}\text { Formula code } \\
\text { with mannitol }\end{array}$ & $\begin{array}{l}\text { Ratio of } \\
(\mathbf{D}: \mathbf{C})^{\dagger}\end{array}$ & $\begin{array}{l}\text { Weight of the } \\
\text { drug (mg) }\end{array}$ & $\begin{array}{l}\text { Weight of the } \\
\text { carrier (mg) }\end{array}$ \\
\hline PMVPVP-1 & PMVPEG-1 & PMVMN-1 & $1: 1$ & 40 & 40 \\
PMVPVP-2 & PMVPEG-2 & PMVMN-2 & $1: 3$ & 40 & 80 \\
PMVPVP-3 & PMVPEG-3 & PMVMN-3 & $1: 5$ & 40 & 200 \\
PMVPVP-4 & PMVPEG-4 & PMVMN-4 & $1: 9$ & 40 & 450 \\
\hline
\end{tabular}

air oven at $45^{\circ} \mathrm{C}$ to form dry granules. Then the mixture was taken and passed through sieve and the granules were collected and further evaluated (David, 2002; Vidyadhara et al., 2011).

Preparation of physical mixtures of valsartan by blending method

The physical mixtures of valsartan were prepared with the blends of drug and carriers in different ratios with increasing concentration of the carriers (Table 3 ). These blends were prepared by mixing drug and the required amount of carrier in a mortar and pestle for 20 minutes. The ratios and weights of the ingredients taken are shown in the Tables below. Blends were mixed thoroughly and were passed through 60 mesh screen. These mixtures were then stored in a
Valsartan, spray dried lactose and a portion of crospovidone were sieved and mixed. The mixture was compacted to slugs. The compact slugs obtained were milled and mixed with crospovidone. The blend obtained was then mixed with magnesium stearate and talc and this lubricated mixture was compressed to tablets (Table 4).

\section{CHARACTERIZATION OF DIFFERENT FORMULATIONS}

Evaluation of flow properties for LS formulations

The formulations are evaluated for the following properties like, angle of repose, bulk density, tapped density, Hausner's ratio, Carrs index. 


\section{Drug excipient compatibility studies}

This study was performed to ensure the compatibility between polymers and drug. Fourier transform infrared (FT-IR) spectra were obtained for valsartan, Avicel PH 102, Aerosil 200, and PVP k- 30, PEG individually. Then compatibility of drug was checked with polymers by taking physical mixtures of drug and Avicel PH102; drug and Aerosil 200, drug and drug and PVP k- 30, drug and PEG on FT-IR Instrument (FT-IR 8400s, Shimadzu, Japan). Spectra of drug and polymers were obtained using the potassium bromide disc method. The pellet was prepared with the dry samples by applying 10 tons/ inch ${ }^{2}$ pressure for 10 min while those of films were acquired

Table 4: Formulation of directly compressible tablets

\begin{tabular}{ll}
\hline \multicolumn{1}{c}{ Ingredients } & Weights $(\mathbf{m g})$ \\
\hline Valsartan & 40 \\
Spray dried lactose & 50 \\
crospovidone & 5 \\
Mg. stearate & 2 \\
Talc & 3 \\
Total weight mg/tab & 100 \\
\hline
\end{tabular}

directly. In each case, 100 spectra in the region of 400 to $4000 \mathrm{~cm}$ - 1 were co-added with a resolution of $4 \mathrm{~cm}^{-1}$.

\section{Powder X-Ray diffraction analysis}

The crystallinity of the prepared LS optimized mixture and SD optimized mixture was studied by XRD. The change in amount of crystallinity was studied. XRD analysis was performed using D-5000 Siemens X- ray diffractometer using Copper K ? $(?=1.5406$ $A^{\circ}$ ) radiation. The data were recorded over a scanning 2? range of 50 to 500 at a step time of $0.045 \mathrm{steps} / 0.5 \mathrm{sec}$.

The pure drug and placebo were analyzed by XRD in same manner and the peak intensity and presence of new peaks were noted. The diffractograms of the optimized LS mixture was superimposed with that of pure drug and placebo.

\section{Differential scanning calorimeter}

The physical nature of the prepared LS optimized mixture and SD optimized mixture was studied by DSC. The conversion of crystalline drug into amorphous form was studied. DSC analysis was performed using TA Instruments Perkin-Elmer pyris differential scanning calorimeter (DSC). The instrument was calibrated with indium standard. $3-5 \mathrm{mg}$ samples were weighed and placed in a closed, hermetic sample pans with pin hole. Thermograms were obtained by heating the sample at a constant rate $10^{\circ} \mathrm{C} / \mathrm{min}$. A dry purge of nitrogen gas $(50 \mathrm{ml} / \mathrm{min})$ was used for all runs. Samples were heated from $0^{\circ} \mathrm{C}$ to $210.0^{\circ} \mathrm{C}$. The melting point, heat of fusion, disappearance of the crystalline sharp peak of the drug and appearance of any new peak and peak shape were noted.

The pure drug and Aerosil, and Avicel were analyzed by DSC in same manner and the melting point and heat of fusion values were noted. The thermogram of the LS optimized formulation was superimposed with that of pure drug and Avicel and Aerosil materials.

\section{Assay}

Accurately weighed samples equivalent to 40 $\mathrm{mg}$ of drug was taken in a $100 \mathrm{ml}$ volumetric flask; $10 \mathrm{ml}$ methanol was added to dissolve the drug. The volume was made to $100 \mathrm{ml}$ with phosphate buffer. The dispersion was filtered using Whatmann filter paper. A $10 \mathrm{ml}$ aliquot of the above solution was taken and diluted to $100 \mathrm{ml}$. The volume was made to $100 \mathrm{ml}$ with buffer medium separately. Dispersions were filtered and $1 \mathrm{ml}$ aliquot of the above solutions were taken and diluted to $10 \mathrm{ml}$ with buffer medium respectively. The concentration of the resultant solution was 10 $\mu \mathrm{g} / \mathrm{ml}$. The absorbance of these solutions were determined at $248 \mathrm{~nm}$ against the blank. The percentage assay was calculated from the standard curve.

\section{In vitro dissolution studies}

The dissolution studies were performed in dissolution apparatus using paddle method (USP II). Dissolution studies were carried out using $1000 \mathrm{ml}$ of phosphate buffer $(\mathrm{pH} \mathrm{6.8)}$ at $37 \pm 0.5^{\circ} \mathrm{C}$ at $50 \mathrm{rpm}$. Valsartan $40 \mathrm{mg}$ or its 
Table 5: Flow property evaluation studies.

\begin{tabular}{llllll}
\hline $\begin{array}{l}\text { Formulation } \\
\text { no* }\end{array}$ & $\begin{array}{l}\text { Angle of } \\
\text { repose }(\mathbf{)}\end{array}$ & $\begin{array}{l}\text { Bulk density } \\
\left(\mathbf{g m} / \mathbf{c m}^{3}\right)\end{array}$ & $\begin{array}{l}\text { Tapped } \\
\text { density } \\
\left(\mathbf{g m} / \mathbf{c m}^{3}\right)\end{array}$ & $\begin{array}{l}\text { Hausner's } \\
\text { ratio }\end{array}$ & $\begin{array}{l}\text { Compressibility } \\
\text { index }(\%)\end{array}$ \\
\hline LSVPG 1 & $32.27 \pm 1.31$ & $0.355 \pm 0.018$ & $0.415 \pm 0.004$ & $1.31 \pm 0.012$ & $21.30 \pm 0.012$ \\
LSVPG 2 & $29.83 \pm 0.67$ & $0.378 \pm 0.006$ & $0.438 \pm 0.006$ & $1.48 \pm 0.024$ & $18.10 \pm 0.029$ \\
LSVPG 3 & $37.32 \pm 0.49$ & $0.394 \pm 0.010$ & $0.482 \pm 0.001$ & $1.37 \pm 0.013$ & $23.88 \pm 0.067$ \\
LSVPG 4 & $36.27 \pm 1.53$ & $0.431 \pm 0.002$ & $0.521 \pm 0.003$ & $1.32 \pm 0.021$ & $25.27 \pm 0.371$ \\
LSVPG 5 & $39.92 \pm 1.27$ & $0.409 \pm 0.006$ & $0.525 \pm 0.008$ & $1.23 \pm 0.026$ & $19.45 \pm 0.18$ \\
LSVPEG 6 & $32.81 \pm 0.73$ & $0.338 \pm 0.010$ & $0.425 \pm 0.002$ & $1.12 \pm 0.033$ & $26.84 \pm 0.092$ \\
LSVPEG 7 & $39.56 \pm .93$ & $0.372 \pm 0.004$ & $0.453 \pm 0.015$ & $1.34 \pm 0.051$ & $23.74 \pm 1.015$ \\
LSVPEG 8 & $38.66 \pm 0.71$ & $0.395 \pm 0.007$ & $0.481 \pm 0.006$ & $1.37 \pm 0.035$ & $27.30 \pm 0.901$ \\
LSVPEG 9 & $40.45 \pm 1.36$ & $0.419 \pm 0.006$ & $0.497 \pm 0.008$ & $1.27 \pm 0.017$ & $23.09 \pm 0.085$ \\
LSVPEG 10 & $37.71 \pm 0.74$ & $0.401 \pm 0.003$ & $0.537 \pm 0.004$ & $1.28 \pm 0.029$ & $21.69 \pm 0.169$ \\
LSVG 11 & $41.32 \pm 0.63$ & $0.342 \pm 0.002$ & $0.434 \pm 0.010$ & $1.38 \pm 0.045$ & $19.38 \pm 0.095$ \\
LSVG 12 & $36.42 \pm 0.83$ & $0.372 \pm 0.004$ & $0.484 \pm 0.002$ & $1.31 \pm 0.039$ & $27.53 \pm 0.35$ \\
LSVG 13 & $40.66 \pm 0.72$ & $0.383 \pm 0.001$ & $0.524 \pm 0.008$ & $1.52 \pm 0.069$ & $22.91 \pm 0.083$ \\
LSVG 14 & $35.49 \pm 0.74$ & $0.415 \pm 0.005$ & $0.515 \pm 0.001$ & $1.39 \pm 0.029$ & $23.34 \pm 0.052$ \\
LSVG 15 & $38.73 \pm 1.20$ & $0.409 \pm 0.009$ & $0.535 \pm 0.013$ & $1.42 \pm 0.036$ & $26.27 \pm 0.026$ \\
DCT & $32.27 \pm 0.73$ & $0.354 \pm 0.006$ & $0.476 \pm 0.003$ & $1.32 \pm 0.029$ & $28.97 \pm 0.076$ \\
\hline
\end{tabular}

equivalent amount of tablet was added to phosphate buffer. The volume of dissolution medium was adjusted to $1000 \mathrm{ml}$ by replacing with $5 \mathrm{ml}$ of fresh phosphate buffer. Solutions were immediately filtered and analyzed spectrophotometrically at $248 \mathrm{~nm}$. The dissolution profile was constructed by plotting percentage cumulative drug release versus time.

Similarly dissolution studies were performed for pure drug and directly compressible tablets.

\section{RESULT AND DISCUSSIONS}

In the experimental section, attempts were made to prepare LS compacts and solid dispersions of valsartan using different excipient ratios. The optimized LS compacts were formulated into tablets and were evaluated for various quality control parameters. The optimized LS compacts, solid dispersion by kneading technique were characterized by DSC and X-RD studies. The LS compacts solid dispersions DCTS physical mixtures were observed for the in vitro dissolution.

\section{Evaluation of flow properties for LS formulations}

Results of measurements such as angle of repose, compressibility index and Hausner's ratio were given in Table 5. From the Table 5, all the formulations were found to be within

Table 6: Interpretation of valsartan IR graph.

\begin{tabular}{cccc}
\hline S. No & Region in $\mathbf{~ c m}^{-1}$ & Type of vibration & Functional group Present \\
\hline 1 & 2962.46 & CH Stretch & Aliphatic \\
2 & 1604 & C-0 stretch & Carboxylic acid \\
3 & 2927.74 & C-H stretch & Aliphatic \\
4 & 1730 & C=O stretch & Amide \\
\hline
\end{tabular}




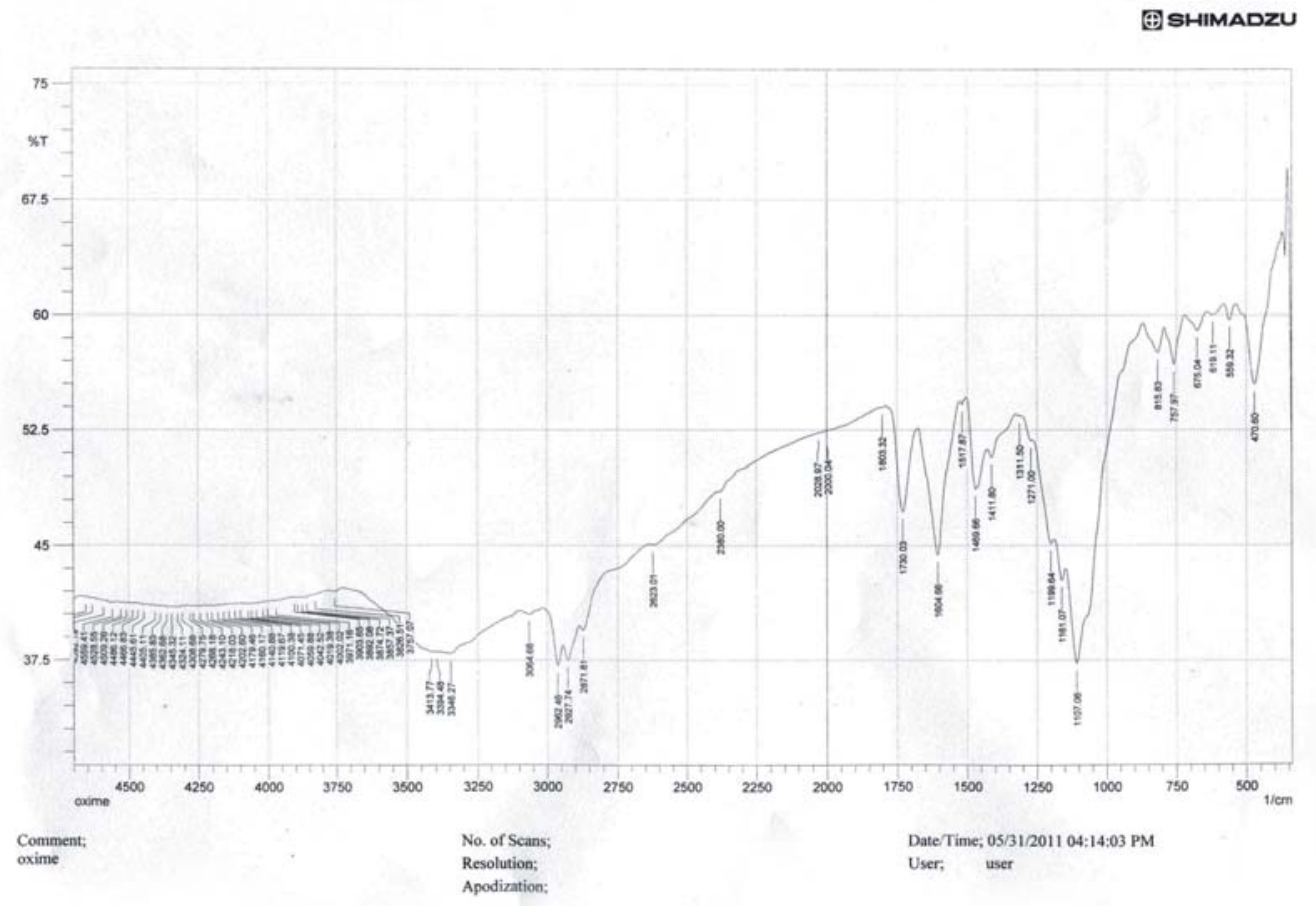

Figure 1: Spectral analysis of valsartan pure drug by FTIR.

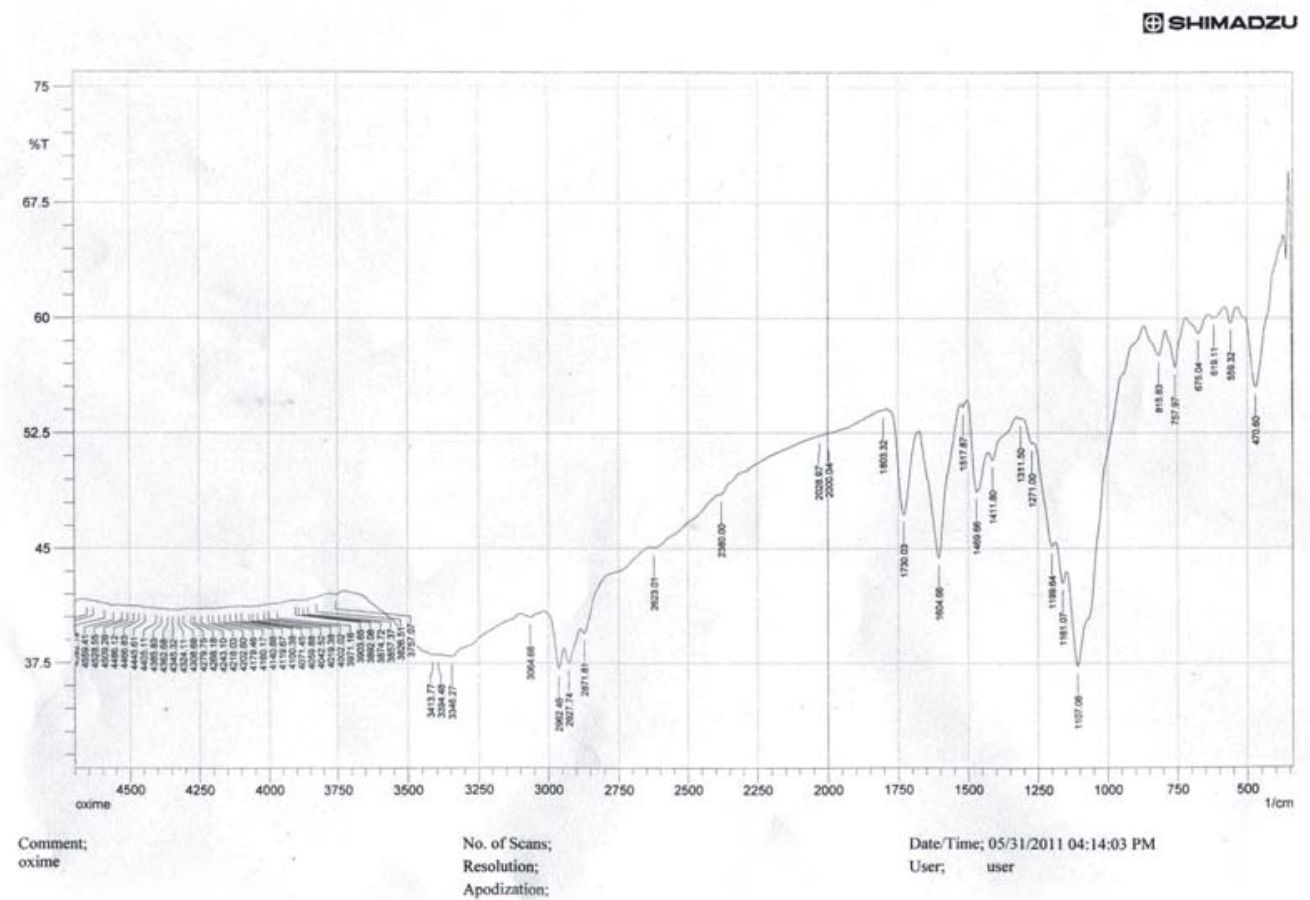

Figure 2: Spectral analysis of LS physical mixture by FTIR. 


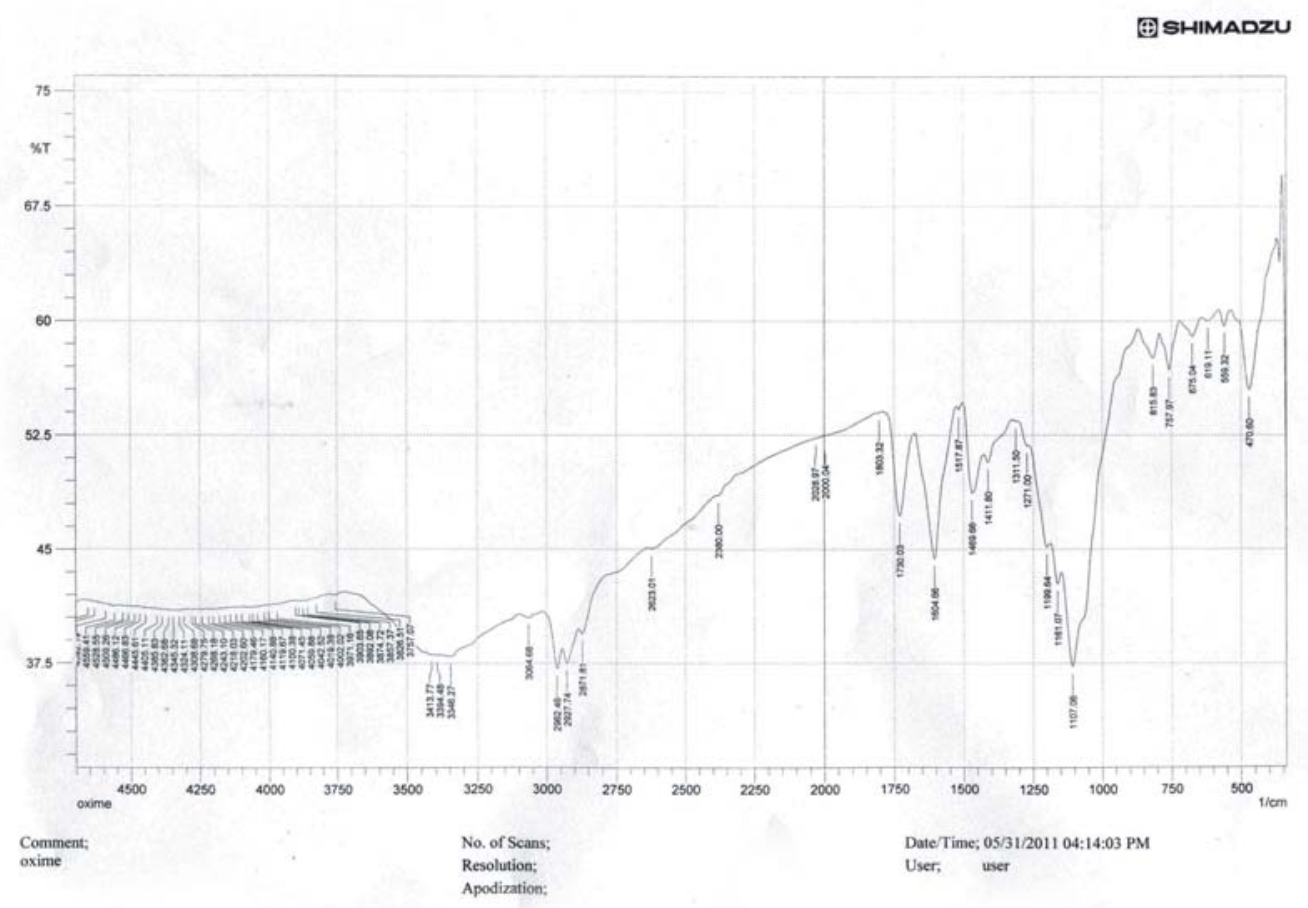

Figure 3: Spectral analysis of SD mixture with mannitol.

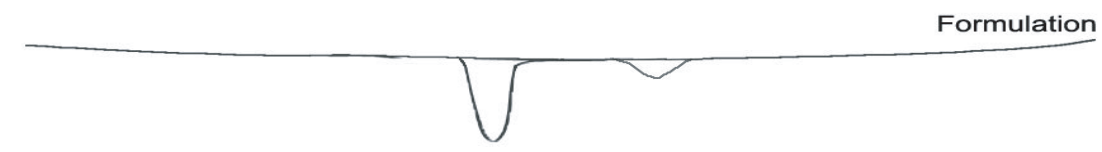

Mannitol

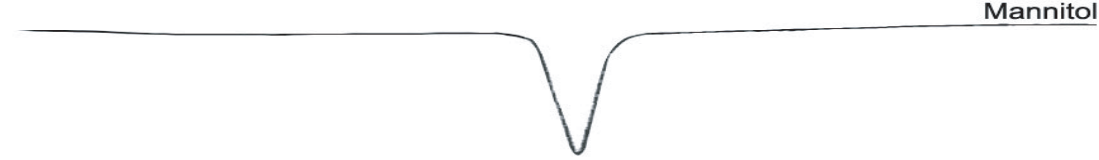

Pure Drug

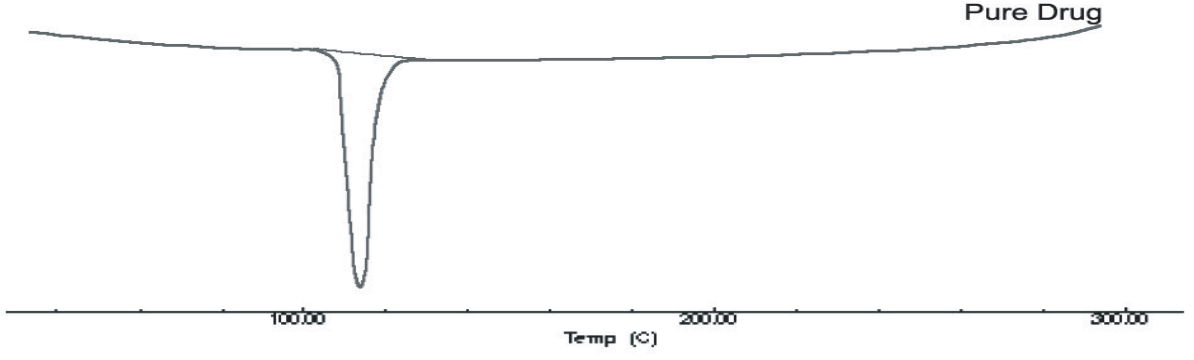

Figure 4: DSC thermograms of pure drug, mannitol and SDVMN3 formulation 

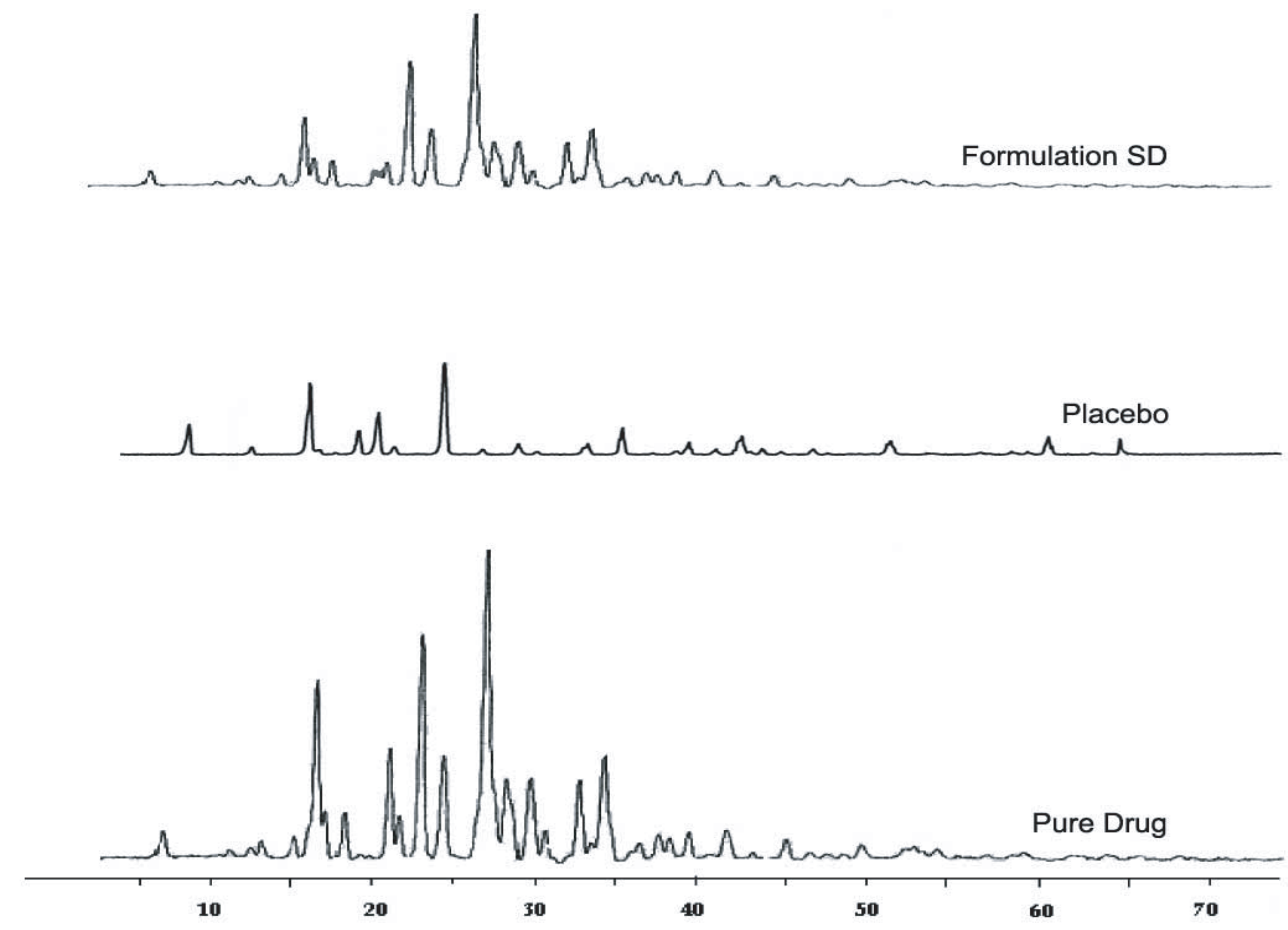

Figure 5: XRD patterns of pure drug, placebo and LSVPG4 formulation.

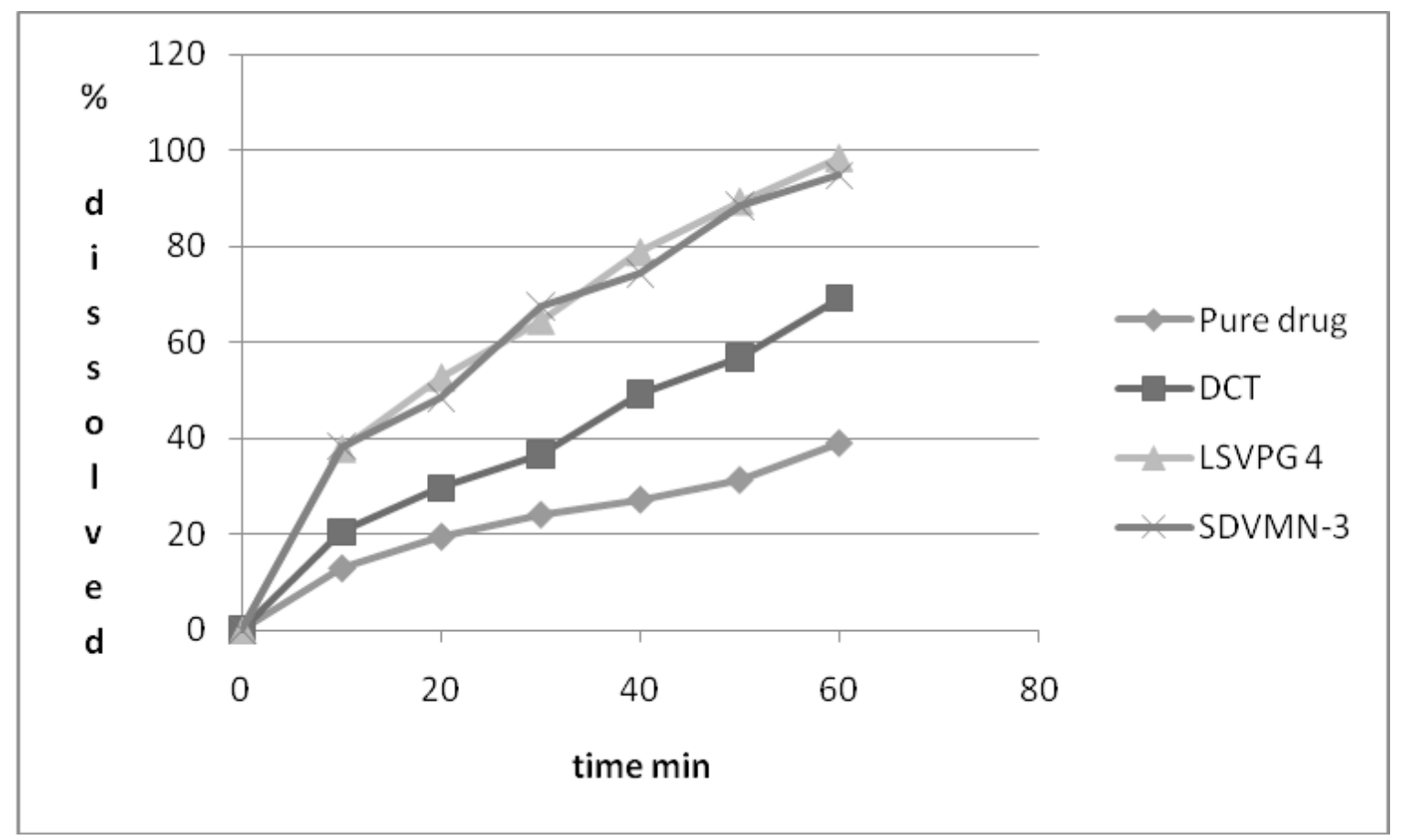

Figure 6: Comparative release profiles of optimized formulations LSVPG4 and SDVMN3 with pure drug, DCT. 
the specification limits. Moreover it can be concluded that LSVPG4 was the best formulation prepared with suitable flow properties and pre compression studies when compared to other formulations.

The IR spectra (Figure 1, Figure 2, Figure 3, Table 6 ) of the various carrier material used in the formulation of liquisolid compacts and solid dispersion represent no interactions of the carrier material with the drug molecule as these carrier materials have not shown any peaks at the drug wave number, hence no interactions were found.

\section{Thermal analysis by DSC}

The physical nature of the prepared SD physical mixture of valsartan with SDVMN3 was studied by DSC (Figure 4). The melting point, peak onset and appearance of any new peak are noted. Similarly, SD formulation and the pure drug were analyzed by DSC in same manner and the melting point and onset of peak values were noted.

The thermograms of the SD mixture SDVMN3 were superimposed with pure drug and formulation and the results were compared. Figure number 4 gives the superimposed thermograms of SD formulation and pure drug.

DSC of pure drug showed a sharp characteristic endothermic peak at $1160 \mathrm{C}$ corresponding to the melting point of valsartan, thus it signifies the presence of valsartan in crystalline state. The thermogram of mannitol showed a broad endothermic peak at $170^{\circ} \mathrm{C}$. However SDVMN3 had showed a characteristic new sharp peak at $132^{\circ} \mathrm{C}$. From DSC studies, it can be concluded that the drug is converted into amorphous form, thus it determines drug in the carrier material, so the drug dissolution would be enhanced.

\section{Crystallinity by XRD}

The crystallinity of the prepared SD mixture of valsartan SDVMN3 was studied by XRD (Figure 5). The change in amount of crystallinity was studied. The pure drug and SD formulation were analyzed by XRD in same manner and the peak intensity and presence of new peaks were noted. The diffractograms of the SD formulation SDVMN3 was superimposed with that of pure drug and placebo.

The $x$ ray diffraction pattern of pure drug exhibited sharp, highly intense and less diffused peaks indicating the crystalline nature of drug at 2 diffraction angels of $20.5^{\circ}$ and $27.8^{\circ}$ as shown in Figure 5. The SD powder X-ray diffraction showed a diffraction peak at 2 angle of $25.0^{\circ}$ belonging to mannitol indicating the crystalline state. The peaks remained changed but their relative intensity of peaks were decreased which might be due to the dilution of the drug and the crystallinity of the drug was converted to amorphous form indicating the valsartan solubilization in the carrier material that absorbed. Thus the reduced crystallinity was due to SD system formation. This may be due to amorphization or solubilization of valsartan in SD system contributes improvement in dissolution rate.

\section{Comparison of the dissolution data of pure drug, DCT, LSVPG4 and SDVMN4 formulations}

The comparison between the dissolution rate of drug was carried out between pure drug, DCT, LS compact (LSVPG4), and SDVMN3 to determine the optimized formulation.

The fig no 6 depicts the comparative drug release of pure drug, DCT, and optimized formulation of LSVPG 4 and SDVMN3, thus the increased dissolution rate was found to be for the LSVPG4, this might be due to the highest solubility of valsartan drug in propylene glycol, and also may be due to the increased wettability of the drug molecules, and also the carrier coating material ratio (20:1) may be a reason as they adsorb the drug molecules and thus they make the drug exposed to the dissolution media. The overall rank order given for the various formulations when compared to pure drug and DCT was LSVPG4> SDVMN3> DCT > pure drug (Figure 6).

\section{CONCLUSION}

Valsartan being a poorly water soluble drug can be made to provide a better therapy if drug is released effectively and this is achieved by formulating drug as liquisolid compact or solid dispersion tablet which was the rationale of the present study. Results proved that LS formulation of valsartan 
displayed higher dissolution profiles than other formulations prepared by solid dispersion, DCT, and pure drug. The overall rank order given for the various formulations when compared to pure drug and DCT was LSVPG4> SDVMN3> DCT > pure drug

In conclusion it can be stated that the objective of the study was achieved in improving the solubility of the valsartan using liquisolid technology in comparison to traditional solid dispersion method.

\section{REFERENCES}

David JH (2002). Lipid-Based Systems for Oral Drug Delivery. Enhancing the Bioavailability of Poorly Water Soluble Drugs. Informa Healthcare. USA.

Hecq, JJ (2006). Development, characterization and evaluation of crystalline nanoparticles for enhancing the solubility, the dissolution rate and the oral bioavailability of poorly water-soluble drugs. Open thesis. 11(17).

Javadzadeh Y, Jafari- Navipour B, Nokhodchi A (2007). Liquisolid technique for dissolution rate enhancement of a high dose water-insoluble drug carbamazepine. International journal of Pharmaceutics. 341(1-2):26-34 http://dx.doi.org/10.1016/j.ijpharm.2007.03.034 PMid:17498898

Spireas S, Sadu S, Grover R (1998). In vitro release evaluation of hydrocortisone liquisolid tablets. Journal of Pharmaceutical Sciences. 87(7): 867-872. http://dx.doi.org/10.1021/js970346g PMid:9649356

Spireas S, Bolton SM (1999). Liquisolid systems and methods of preparing same. Google Patents. Patent number: 5800834
Spireas S, Sadu S (1998). Enhancement of prednisolone dissolution properties using liquisolid compacts. International Journal of Pharmaceutics. 166(2): 177-188. http://dx.doi.org/10.1016/S0378-5173(98)00046-5

Sugawara M, Kadomura S, He X, Takekuma Y, Kohri N, Miyazaki K (2005). The use of an in vitro dissolution and absorption system to evaluate oral absorption of two weak bases in $\mathrm{pH}$-independent controlled-release formulations. European Journal of Pharmaceutical Sciences. 26(1): 1-8.

http://dx.doi.org/10.1016/j.ejps.2005.02.017

PMid:15961297

Aleti SR, Rangaraju D, Kant A, Shankraiah MM, Venkatesh JS, Rao RN, Nagesh C (2011). Solubility and Dissolution Enhancement of Cefixime Using Natural Polymer by Solid Dispersion Technique. International Journal of Research in Pharmacy and Chemistry. 1(2): 283-288.

Vidyadhara S, Babu JR, Sasidhar RLC, Ramu A, Prasad SS, Tejasree M (2011). Formulation and evaluation of glimepiride solid dispersions and their tablet formulations for enhanced bioavailability. International Journal of Advances in Pharmaceutical sciences. 2(1).

Yalkowsky S, Rubino JT (1985). Solubilization by cosolvents I: Organic solutes in propylene glycol-water mixtures. Journal of pharmaceutical sciences. 74(4): 416421. http://dx.doi.org/10.1002/jps.2600740410 PMid:3999002

Youn YS, Jung JY, Oh SH, Yoo SD, Lee KC (2006). Improved intestinal delivery of salmon calcitonin by Lys 18-amine specific PEGlytion: Stability, permeability, pharmacokinetic behavior and in vivo hypocalcemic efficacy. J Control Release. 114:334-342. http://dx.doi.org/10.1016/j.jconrel.2006.06.007 PMid:16884808 